\title{
Effects of a continuous care model on perceived quality of life of spouses of haemodialysis patients
}

A. Rahim, ${ }^{1,2}$ F. Alhani, ${ }^{1}$ F. Ahmadi, ${ }^{1}$ M. Gholyaf ${ }^{3}$ and M. R. Akhoond ${ }^{4}$

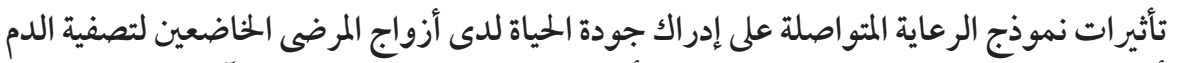

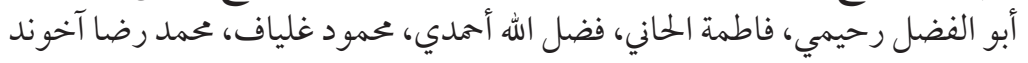

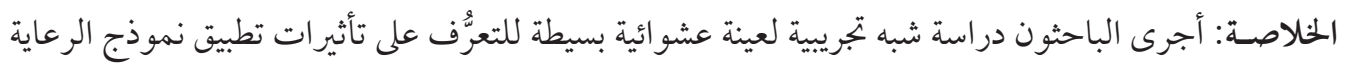

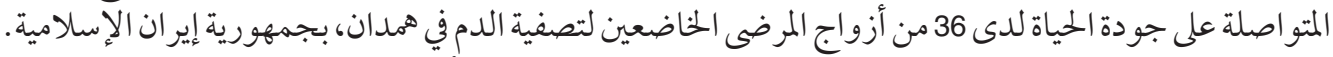

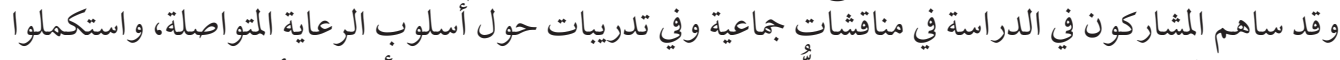

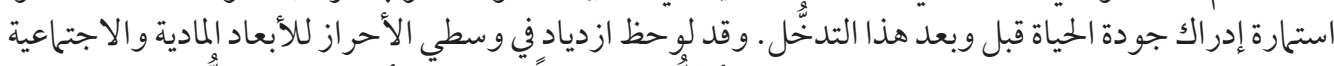

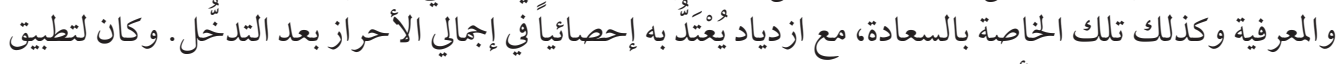

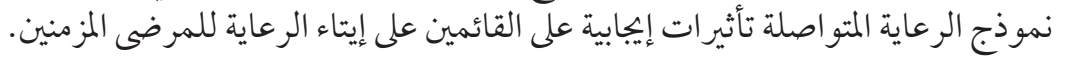

ABSTRACT We carried out a semi-experimental study with simple randomized sampling to study the effects of applying a continuous care model on the quality of life of 36 spouses of haemodialysis patients in Hamedan, Islamic Republic of Iran. Participants took part in group discussions and training on the continuous care approach and completed the Perceived Quality Of Life (PQOL) questionnaire before and after the intervention. Mean scores on the physical, social and cognitive dimensions, as well as happiness and total scores significantly increased after the intervention. Applying a continuous care model has positive effects on the caregivers of chronic patients.

Effets d'un modèle de soins continus sur la qualité de vie ressentie par les conjoints de sujets hémodialysés

RÉSUMÉ Nous avons réalisé une étude semi-expérimentale sur la base d'un échantillonnage aléatoire simple afin d'étudier les effets de l'application d'un modèle de soins continus sur la qualité de vie de 36 conjoints de sujets hémodialysés à Hamedan (République islamique d'Iran). Les participants ont participé à des discussions de groupe et à des formations sur le concept de soins continus et ont complété le questionnaire sur la qualité de vie ressentie (PQOL) avant et après l'intervention. Les scores moyens relatifs aux aspects physiques, sociaux et cognitifs, de même que le score relatif au bonheur et les scores totaux, ont augmenté de façon significative après l'intervention. L'application d'un modèle de soins continus a des effets positifs sur les aidants de patients chroniques.

\footnotetext{
${ }^{1}$ Department of Nursing; ${ }^{4}$ Department of Biostatistics, Tarbiat Modares University, Tehran, Islamic Republic of Iran (Correspondence to F.Alhani: Alhani_F@modares.ac.ir).

${ }^{2}$ Department of Nursing and Midwifery, Zanjan University of Medical Science, Zanjan, Islamic Republic of Iran.

${ }^{3}$ Department of Nephrology, Hamedan University of Medical Science, Hamedan, Islamic Republic of Iran. Received: 08/10/06; accepted: 04/02/07
} 


\section{Introduction}

Despite improvements in health and medical sciences, the number of people suffering from renal failure has been steadily increasing worldwide, and accordingly the number of haemodialysis (HD) patients undergoing medical treatment has increased. For example, in Germany approximately 156 per million people develop end-stage renal disease each year, with prevalence slightly more than 700 per million [1].

Chronic illness affects not only the lives of those suffering from the disease, but also those family members who care for them [2]. Caregivers of patients with chronic disease are affected differently depending on the characteristics of the caregiver and the patient $[3,4]$. Family caregivers report missing work, taking personal days and quitting work or retiring early to provide care [5]. Caregiving is also an independent risk factor for higher levels of depression [6], anxiety and stress [7], mental disease, changes in family functioning [8] and mortality [9].

Studies of HD emphasize patient adaptation to dialysis, yet few studies deal directly with the spouse of the dialysis patient, who is intimately involved with the patient's treatment [10]. Caregivers of HD patients may feel a heavy burden because they are obliged to play an important role in supporting patients on dialysis [11]. Depression in the caregivers of persons with multiple sclerosis was related to the physical, emotional and health status of the patients at baseline and/or at 12-months follow-up [12]. Caregivers of HD patients may experience a significant burden and an adverse effect on the emotional dimension of their quality of life (QOL). Therefore, social support and psychological interventions should be considered to improve caregivers' lives and patients' outcomes [13].
Ahmadi has developed a continuous care model for patients with coronary artery disease in the Islamic Republic of Iran (Figure 1) [14]. The aim was to establish and maintain a dynamic and continuous care relationship so as to raise awareness about the caring performance and to improve and promote the QOL of the clients. A continuous and effective care relationship isa dynamic, interactive and mutual relationship between the nurse and the patient and his/ her family. In the development of such a relationship, both the quality of care and the content, method and nature of the services offered come to the fore. The continuous care model aims to be dynamic/flexible, client/family-oriented, empowering/selfenabling, holistic and collaborative.

In view of the importance of QOL for HD patients, this research aimed to study the effects of applying a continuous care model on the QOL of the spouses of HD patients.

\section{Methods}

\section{Study design and sample}

We carried out a quasi-experimental study from February to September 2005 of 36 spouses of HD patients in a referral dialysis centre in Hamadan, Islamic Republic of Iran. The participants were selected using simple randomized sampling; the inclusion criteria were the spouses of patients who had undergone HD for more than 6 months and who agreed to enter the study. The study was approved by the ethics committee of Hamedan University of Medical Sciences.

\section{Data collection}

Two questionnaires were used. The first collected the spouses' characteristics, such as age, sex, number of family members, 


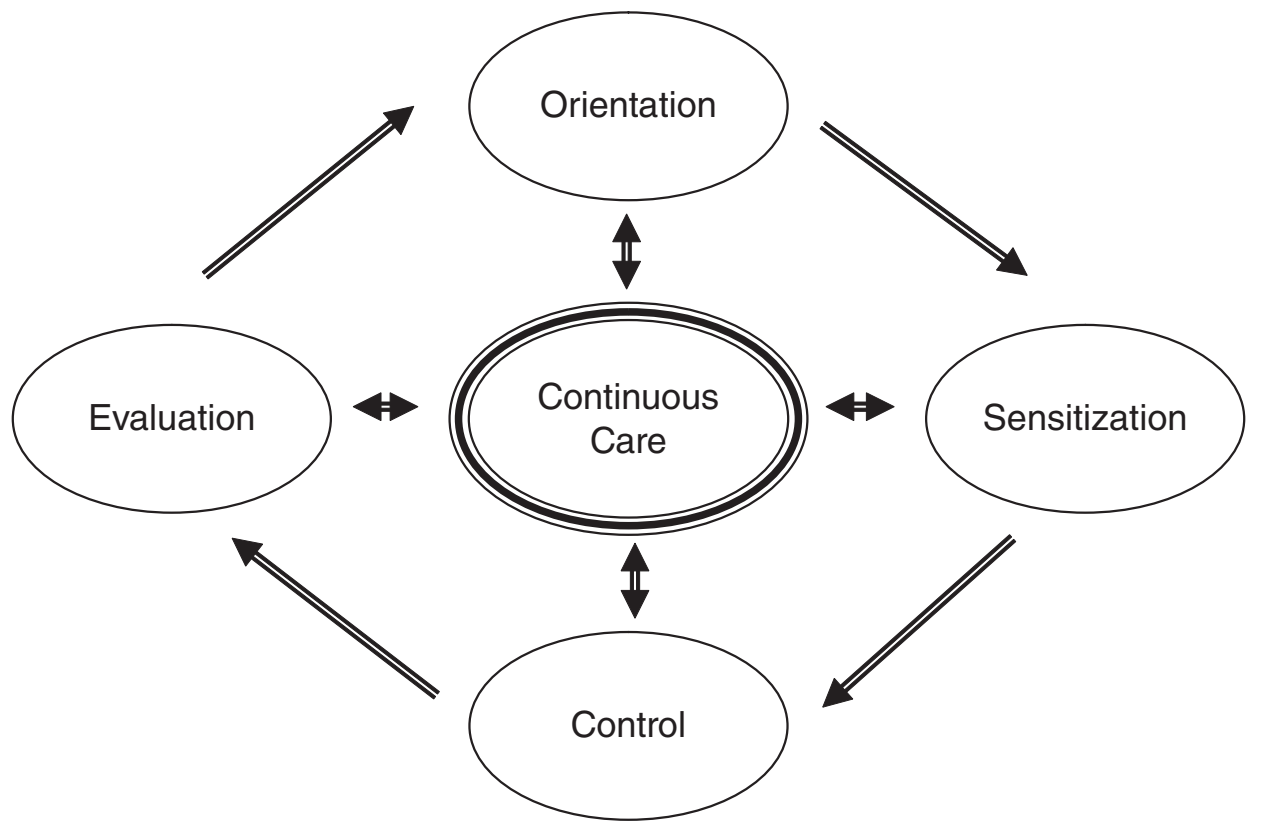

Figure 1 Stages of the continuous care model [source: 15]

education, job, insurance cover and family income level (self-defined). The second was the Perceived Quality of Life (PQOL) questionnaire of Patrick et al. which was aimed at evaluating the QOL of the spouses. PQOL is a 20 -item tool, with 19 items in 3 subscales (physical, social and cognitive health satisfaction), plus 1 item for rating happiness, a self-report measure that assesses satisfaction with the major categories of fundamental life needs and categories of functioning [15]. All items used a $0-10$ scale (very dissatisfied/unhappy to very satisfied/happy). To measure the validity and reliability of the questionnaire, content validity and Cronbach alpha coefficient $(\alpha$ $=0.9$ ) were assessed.

Before the intervention participants were familiarized with and briefed on the research goals and how to complete the questionnaires. They repeated the questionnaires 3 months after the intervention.

The intervention was carried out with 36 participants divided into 3 groups. The process proceeded in 4 phases: familiarization, sensitization, control and evaluation.

- The familiarization phase aimed at an accurate diagnosis of problems with HD care, motivating the clients and determining their needs for the care process. The researchers coordinated a meeting which lasted 15-30 minutes during which the patient and his/her family were familiarized with the process, briefed on mutual expectations and advised about the continuation of the care-treatment relationship.

- The sensitization process aimed to engage the patient and the family in the application of the continuous care ap- 
proach. Negotiating this phase is critical to the success of the plan. The participants tok part in counselling sessions, group discussions, presentations and question-and-answer sessions (in 3 groups) about the nature and diversity of needs and problems facing the HD patient and his/her family to diagnose new problems, and to sensitize and motivate the clients to persevere with the process. There were 4-6 sessions lasting 1-2 hours. When the problem was not within the scope of the researchers' knowledge and expertise, the patient and the family were referred to a specialist.

- The remaining time was devoted to the continuation of the caring process (control phase), and weekly sessions were held with the participants. Problem checklists were completed regularly with the aim of reviewing and dealing with new care problems, considering the dynamic nature of health and disease, and starting the sensitization phase for new problems.

- The fourth step was the evaluation, which continued throughout all stages of the model.

\section{Analysis}

The PQOL score was from $0-100$ and categorized as: weak (score 0-33.3, average (score 33.4-66.6) and good (66.7-100). Descriptive, multiple regression and paired $t$-test statistical tests were used to analyse the collected data.

\section{Results}

There were 36 research participants: $50 \%$ were men; $41.7 \%$ were in the age range 40 59 years; $72.2 \%$ were illiterate or had only primary education; $44.4 \%$ were housewives and $66.7 \%$ reported their family income level as poor (Table 1).
Before the intervention, spouses' scores in the PQOL were weak in the physical [mean 33.9; standard deviation (SD) 16.3] and cognitive (mean 12.7; SD 6.3) dimensions, but less so for social relations (mean 57.6; SD 26.7).

After the intervention there was a significant improvement in the mean scores for spouses' QOL in all dimensions of the PQOL: physical $(P=0.0001)$, social $(P$ $=0.0001)$ and cognitive $(P=0.0001)$ (Table $2)$. There was also a significant increase in the self-reported level of happiness experienced by spouses, from a mean score of 4.7 (SD 2.8) to 5.3 (SD 2.5) $(P=0.001)$ (Table $2)$. The mean total PQOL score increased significantly from 54.9 (SD 23.4) before to 64.8 (SD 21.9) after the intervention $(P$ $=0.001)($ Table 2$)$.

\begin{tabular}{|c|c|c|}
\hline Variable & No. & $\%$ \\
\hline \multicolumn{3}{|l|}{ Sex } \\
\hline Male & 18 & 50.0 \\
\hline Female & 18 & 50.0 \\
\hline \multicolumn{3}{|l|}{ Income } \\
\hline Good & 0 & 0 \\
\hline Average & 12 & 33.3 \\
\hline Poor & 24 & 66.7 \\
\hline \multicolumn{3}{|l|}{ Age (years) } \\
\hline 20-39 & 12 & 33.3 \\
\hline $40-59$ & 15 & 41.7 \\
\hline$\geq 60$ & 9 & 25.0 \\
\hline \multicolumn{3}{|l|}{ Education } \\
\hline Illiterate & 12 & 33.3 \\
\hline Primary & 14 & 38.9 \\
\hline High school & 7 & 19.5 \\
\hline University & 3 & 8.3 \\
\hline \multicolumn{3}{|l|}{ Job } \\
\hline Housewife & 16 & 44.4 \\
\hline Employee & 7 & 19.4 \\
\hline Self-employed & 7 & 19.4 \\
\hline Manual worker & 6 & 16.7 \\
\hline
\end{tabular}


Multiple regression analysis showed no significant difference $(P<0.05)$ in the QOL level (total and by dimension) perceived by the participants in relation to their individual characteristics (e.g. age, sex, income level, education level and job) $(P<0.05)$ (Table 3).

\section{Discussion}

Attending to the impact of chronic illness on family members is important because the physical and emotional health of family caregivers has the potential to influence the health, welfare and successful rehabilitation of persons with such illness [2].

Uncontrollable variables in this research were the clients' knowledge, background, prior experience and interest in accepting the model and its details, and the mental and emotional status and cultural roots of the patients' and their families'. Another limitation of the research was that the long-term effects of the process were not assessed.

\begin{tabular}{|c|c|c|c|c|}
\hline \multicolumn{5}{|c|}{$\begin{array}{l}\text { Table } 2 \text { Mean scores of participants for } \\
\text { subscales of the Perceived Quality of Life } \\
\text { questionnaire, happiness and the total score } \\
\text { before and after the intervention }\end{array}$} \\
\hline Variable & $\begin{array}{l}\text { Mean } \\
\text { score }\end{array}$ & SD & $t$-value & $P$-value \\
\hline \multicolumn{5}{|l|}{ Physical } \\
\hline Before & 33.9 & 16.3 & -9.5 & $<0.001$ \\
\hline After & 37.8 & 15.9 & & \\
\hline \multicolumn{5}{|l|}{ Social } \\
\hline Before & 57.6 & 26.7 & -12.6 & $<0.001$ \\
\hline After & 66.8 & 25.2 & & \\
\hline \multicolumn{5}{|l|}{ Cognitive } \\
\hline Before & 12.7 & 6.3 & -7.4 & $<0.001$ \\
\hline After & 14.7 & 5.6 & & \\
\hline \multicolumn{5}{|l|}{ Happiness } \\
\hline Before & 4.7 & 2.8 & -3.5 & $<0.001$ \\
\hline After & 5.3 & 2.5 & & \\
\hline \multicolumn{5}{|l|}{ Total } \\
\hline Before & 54.9 & 23.4 & -14.9 & $<0.001$ \\
\hline After & 64.8 & 21.9 & & \\
\hline
\end{tabular}

\begin{tabular}{|c|c|c|c|c|c|}
\hline Model & $\begin{array}{l}\text { Reference } \\
\text { category }\end{array}$ & Parameter & SE & $t$-value & $P$-value \\
\hline$\overline{\text { Age }}$ & & 0.38 & 0.87 & 0.437 & 0.666 \\
\hline Sex & Male & 20.06 & 29.87 & 0.674 & 0.507 \\
\hline Female & & -9.23 & 36.35 & -0.254 & 0.802 \\
\hline Job & Manual worker & 4.62 & 32.46 & 0.142 & 0.889 \\
\hline Housewife & & 10.30 & 27.46 & 0.373 & 0.713 \\
\hline Self-employed & & 6.84 & 20.47 & 0.334 & 0.741 \\
\hline Education & Illiterate & 28.61 & 32.74 & 0.874 & 0.391 \\
\hline Primary & & -2.12 & 53.84 & -0.039 & 0.969 \\
\hline High school & & 37.87 & 48.39 & 0.783 & 0.441 \\
\hline University & & -64.31 & 67.35 & -0.955 & 0.349 \\
\hline Income & Poor & 59.59 & 52.79 & 1.129 & 0.27 \\
\hline Average & & 0.38 & 0.87 & 0.437 & 0.666 \\
\hline Good & & 20.06 & 29.87 & 0.674 & 0.507 \\
\hline (Intercept) & & 59.59 & 52.74 & 1.129 & 0.27 \\
\hline
\end{tabular}

$S E=$ standard error

المجلة الصحية لشرق المتوسط، منظمة الصحة العالمية، المجلد الخامس عشر، العدد ع، 9 + • 
Our findings show that before the intervention the QOL scores of spouses of HD patients were weak (except in social relations). However, the participants' mean score of different dimensions of QOL and their total score of QOL increased significantly after the intervention. Therefore, it can be concluded that the application of the individual, group and family training in the continuous care model promoted improvements in the 3 dimensions of spouses' QOL. Previous studies in the Islamic Republic of Iran showed that applying this caring model had significant effects on QOL of diabetic [15] and schizophrenic [16] patients.

Previous studies have documented how caring for chronically ill family members or significant others at home influences multiple aspects of caregivers' lives. These effects may include worsened physical health, impaired social and family life, and increased stress, anxiety and depression. A study by Belasco and Sesso on the problems and QOL of the caregivers of HD patients showed that spouses caring for patients suffering from end-stage renal disease had a lower QOL than the general population and were adversely affected in physical dimensions, mental health and joviality [13]. Research by Campbell et al. on patients with prostrate cancer revealed that disorders in physical and psychosocial performance are an adverse side-effect of prostrate cancer treatment. Spouses/partners of patients often face multiple demands, including helping the patient cope with side-effects of treatment, such as erectile dysfunction and urinary incontinence, and providing support [17].

It is important to understand and distinguish between the attitudes, attributes and psychosocial characteristics of both patients and caregivers to plan and provide effective treatment interventions with the aim of improving the QOL for both groups [18].

In conclusion, applying a continuous care model to the care of patients undergoing HD makes a significant improvement to all areas of the spouses' QOL.

\section{Acknowledgements}

We would like to thank all the clients for their generous help in this research and our particular thanks go to the nurses in the HD ward of Ekbatan Hospital in Hamadan. Finally warm thanks to the nursing department and research vice-presidency of the Faculty of Medicine of Tarbiat Modarres and Hamedan Medical Science University for their spiritual support in this research.

\section{References}

1. Franke GH et al. Aspects of quality of life through end-stage renal disease. Quality of life research, 2003, 12:103-15.

2. Han B, Haley WE. Family caregiving for patients with stroke: review and analysis. Stroke, 1999, 30:1478-85.

3. Brodaty $\mathrm{H}$, Luscombe G. Psychological morbidity in caregivers is associated with depression in patients with dementia. Alzheimer disease and associated disorders, 1998, 12: 62-70.
4. Donaldson C, Tarrier N, Burns A. Determinants of carer stress in Alzheimer's disease. International journal of geriatric psychiatry, 1998, 13:248-56.

5. United Hospital Fund study finds changes in nation's health care system place daunting new burdens on 25 million unpaid family caregivers who provide nearly \$200 billion in essential services [press release]. New York, United Hospital Fund, 1998 (http://www.uhfnyc.org/

المجلة الصحية لشرق المتوسط، منظمة الصحة العالمية، المجلد الخامس عشر، العدد ع، 9 +. 
press_release 3159/press_release_show. htm?doc_id=99320, accessed 16 October 2008).

6. Yee JL, Schulz R. Gender differences in psychiatric morbidity among family caregivers: A review and analysis. Gerontologist, 2000, 40:147-64.

7. Goode KT et al. Predicting longitudinal changes in caregiver physical and mental health: a stress process model. Health psychology, 1998, 17:190-8.

8. Paradiso $\mathrm{C}$. The dialysis patient, the family, and the home health nurse. Home healthcare nurse, 1986, 4:26-34.

9. Bond MJ, Clark MS, Davies S. The quality of life of spouse dementia caregivers: changes associated with yielding to formal care and widowhood. Social science and medicine, 2003, 57:2385-95.

10. Friesen D. A descriptive study of home hemodialysis spouses. Dialysis and transplantation, 1997, 26:310-25.

11. Matsuu K et al. Depression among caregivers of elderly patients on chronic hemodialysis. Fukuoka igaku zasshi, 2001, 92:319-25.

12. Pozzilli $C$ et al. Relationship between emotional distress in caregivers and health status in persons with multiple sclerosis. Multiple sclerosis, 2004, 10:442-6.
13. Belasco AG, Sesso R. Burden and quality of life of caregivers for hemodialysis patients. American journal of kidney diseases, 2002, 39:805-12.

14. Ahmadi F. [Developing and evaluating continuous care model in controlling patients with coronary artery disease] [thesis]. Tehran, Tarbiat Modarres University, 2001 [in Farsi].

15. Ghavami H. [Effects of CCM on diabetic patients' QOL] [MSc thesis]. Department of Nursing, Tehran, Tarbiat Modarres University, 2005 [in Farsi].

16. Anjomanian V. [Effects of CCM on schizophrenic patients' QOL] [MSc thesis]. Tehran, Department of Nursing, Welfare and Rehabilitation University, 2005 [in Farsi].

17. Campbell LC et al. Prostate cancer in African Americans: relationship of patient and partner self-efficacy to quality of life. Journal of pain and symptom management, 2004, 28:433-44.

18. Trail $M$ et al. A study comparing patients with amyotrophic lateral sclerosis and their caregivers on measures of quality of life, depression, and their attitudes toward treatment options. Journal of the neurological sciences, 2003, 209:79-85. 